thin, translucent walls and filled with fluid. In what way can we effect a radical cure? In several ways: first, by injecting the tincture of iodine and then rubbing it about in the sac; secondly, we might cut open the cyst and let it heal by granulation; thirdly, draw a seton through it; fourthly, there is the French method, which consists in drawing off half the contents of the sac and substituting absolute alcohol. This method is sometimes successful, but the iodine injection is the best treatment. To lay open the scrotum is dangerous, because of possible sloughing; and the seton treatment is long and troublesome. One way of using the iodine is to inject a mixture of equal parts of tincture of iodine and water, and then draw it off again. Another method is to inject a small quantity of strong iodine, and allow it to remain in the sac. Before injecting, push the canula well up to its neck in the sac, so as to be sure that no iodine penetrates into the cellular tissue of the scrotum, where it might cause sloughing. The injection of iodine may in some cases be followed by severe pain, extending up the cord, confining the patient to his bed for a fortnight. I shall inject the ordinary tincture of iodine, of the undiluted officinal strength. $I$ use one drachm and leave it in the sac. The patient must not walk after the operation, but must be put to bed to prevent the iodine from running out. If all goes as we wish, in tiventy four hours there will be a smart inflammation followed by adhesion of the opposite walls of the sac.

\title{
AIKEN, SOUTH CAROLINA, AS A HEALTH RESORT.
}

BY ARTHUR H. NICHOLS, M. D.

IT is only within the past quarter of a century that the influence of different climates and atmospheric phenomena upon the human organism in health and disease has been systematically studied; and even now this important agent continues to form a branch of therapeutics consistently and uniformly overlooked both in our text-books and medical schools. The physician is not unfrequently called upon to determine what climate is the most appropriate to the constitution and condition of different invalids, and to the particular disorders from which they are suffering, and it is therefore desirable that he should be somewhat familiar with the climatic characteristics of the prominent health resorts.

Until within a few years the watering-places of Southern Europe have held out superior advantages in the way of hotel accommodations, hygienic cookery, refined society, picture-galleries, and club rooms, all valuable adjuncts in the treatment of despondent, depressed invalids, - and have therefore attracted the mass of those able to travel in

1 Read before the Norfolk District Medical Society, November 13, 1877. 
search of health; whereas the absence of such sources of diversion in our American resorts, their lack of easy accessibility, the dearth of trustworthy physicians, and, finally, the little attention paid by our native hotel proprietors to gastronomical science, have hitherto contributed to render American sanitaria unattractive to strangers, especially those suffering from impaired digestive functions. Since the close of our civil war, however, a very decided change for the better has been effected in the character of the larger health resorts of the Southern States, an improvement attributable partly to the influx of Northern capital, by means of which numerous well-equipped hotels have been started, and partly to the greater facilities for travel afforded by newly-built railroads and the introduction of that luxury of travel, the Pullman car; and as one result of this change the tide of European travel has been already in a measure stemmed. To-day the invalid who shrinks from the discomforts of an ocean voyage can go in one vehicle without change from Boston to South Carolina or Georgia in a journey of but forty-eight hours, while at the more frequented sanitaria, and notably at Aiken, St. Augustine, and Jacksonville, will be found commodious hotels answering every reasonable hygienic requirement, furnished with good taste, and capable of supplying a sound, wellordered repast.

It was the fortune of the writer to make a short visit to Aiken in the month of January, 1877, and the following facts relating to the climate of this locality, which now takes front rank in the list of American health resorts, were collected in part upon the occasion of this visit, and have been in part drawn from the detailed description contained in a brochure ${ }^{1}$ recently published by $\mathrm{Dr}$. Wm. H. Geddings, one of the resident physicians of the place.

The prominent characteristics of the climate of Aiken are its mild winter temperature, with an abundance of warm, sunny days; a dry, bracing air; freedom from malaria; and comparative immunity from fogs and frosts. During the months from November to April inclusive, which constitute the season for Northern visitors, rain falls upon the average but forty-one days, whereas the number of rainy days during the same period at Pau is fifty, at Palermo fifty-eight, at Madeira sixtytwo, and at Rome sixty-five; Nice and Mentone show a smaller number, namely, thirty-one and thirty-eight respectively. The temperature of Aiken bears a close resemblance to the principal health stations of Southern Europe. The mean temperature of the three months November, December, and January is $48.53^{\circ} \mathrm{F}$, or one and a half degrees lower than Nice, Cannes, and Mentone $\left(50^{\circ}\right)$, and six and a half degrees higher than Pau $\left(42^{\circ}\right)$. The months of February, March, and

1 Aiken as a Health Station. By W. H. Geddings, M. D. Charleston, S. C. $187 \%$. 8vo, pp. 31 . 
April give a mean temperature of $55^{\circ} \mathrm{F}$, which corresponds exactly with that of Nice for the same period, and is three degrees higher than that of Mentone. As regards equability it is shown by the reports of the signal officers that the mean diurnal variation in the temperature is less than that of any other health resort of importance in the United States with the exception of San Diego. In this respect, however, it must be admitted that the sanitaria of Europe possess an advantage. The distinguishing feature of the American climate, taken as a whole, as compared with that of Europe is its changeability, manifested in the irregular disturbances and variations that occur in the temperature, winds, humidity, quantity of rain, and clondiness ; and in Aiken abrupt transitions from heat to cold, and vice vers $\hat{a}$, are not unfrequent during the winter months, which, if not guarded against, are apt to prove serious sources of danger to the invalid. During January and the greater part of February there are occasional days when the thermometer falls below freezing-point. Once or twice each year a slight flurry of snow may be seen, the flakes melting as they fall ; and once in five or six years the ground may be whitened with snow for a day or two. The contingency of the prevalence of cold weather is amply provided for, however, within the houses, and I was particularly pleased with the appearance of the generous open fire-places everywhere met with, flanked by piles of oak and pine logs; stoves when used at all being very properly consigned to the halls.

Aiken is charmingly situated upon the brow of a hill elevated about six hundred feet above the sea, overlooking immense evergreen pine forests, and distant but seventeen miles from Augusta, Georgia. The soil is a loose, coarse sand, white and clean on the surface, but mixed with clay, and of a variegated hue in the lower strata. Where the railroad penetrates the hill the lower strata of clay and sand have such a uniform deep-red hue that the sides of the cutting bear every appearance of having been recen:ly painted. It will thus be evident that nothing could insure more perfect drainage than this elerated situation combined with a most porous soil. The sandy soil serves, moreover, to absorb rapidly the rainfall as well as atmospheric moisture, and thus contributes to render the air dry. The dense forests that surround the town furnish attractive drive-ways, and, what is of greater importance, they exercise a considerable influence upon the climate, affording protection against the strong winds of winter, increasing the amount of rainfall, and mitigating the intense heat during the summer. I was also impressed by the resinous or balsamic odors with which the atmosphere was constantly impregnated by the neighboring pines, resembling, it is said, the peculiar odor that prevails at Bournemouth, England, and the Isle of Pines, lying south of Cuba. It was thought by several invalids whom I met that the odors thus exhaled exercised a favorable 
influence in certain disorders of the air passages. It is possible, moreover, that these adjacent forests, by giving out large quantities of oxygen from their leaves, tend to neutralize any miasmatic effluvia approaching from the insalubrious lowlands, and thus afford an insurmountable barrier to the malarious diseases prevalent along the coast. The elevated situation of the place also plays, doubtless, a part in freeing the air from those organic particles which are supposed to promote putrefactive changes, and in thus rendering it clear, pure, and hence antiseptic. Aiken may be classed, then, with Mentone, Nice, Pau, and Madeira among the dry, tonic climates, which produce a bracing, exhilarating effect upon the body, stimulating the functions of the animal economy, favoring the pulmonary and cutaneous exhalations, and tending to deplete the internal organs. It will be understood, therefore, that the therapeutic effect of the air of Aiken would be quite the opposite of that produced by the atonic or relaxing climates such as prevail in most parts of Florida, Cuba, the Bahamas, and Bermudas, the atmosphere of these latter localities being characterized by the habitual presence of a large amount of moisture combined with a high temperature, which tends to produce a feeling of bodily lassitude and mental depression, and has the effect, especially in certain lung affections, of aggravating internal congestion and inflammation.

Dr. Geddings admits that the drawback of the climate, as compared with the Mediterranean resorts, consists in its variability, but contends that this disadvantage is counterbalanced by its greater dryness and the larger extent of country presented to the invalid for walks and drives. For a list of the various disorders for which the air of Aiken is especially commended the reader is referred to the interesting work itself. It may be briefly stated, however, that this climate is particularly indicated in all diseases characterized by anæmia or an impoverished blood, or by a deranged digestion; in bronchitis, where there is a fair amount of secretion; and, finally, in the early stages of pulmonary consumption in its various forms, excepting acute tuberculosis and laryngeal phthisis. There exists another large class for which this tonic air is peculiarly appropriate. It includes those who are making slow or imperfect recoveries after fevers, or who, suffering from no special ailment, require a change of air and relaxation from the cares and anxieties of business ife. With this class of patients the natural tendency to spontaneous cure is favored by exposure to a bright sun and cloudless sky in a mild temperature, but is checked, on the other hand, by prolonged confinement in the insalubrious air of furnace-heated apartments, still more contaminated by the impure emanations inseparable from our large cities. It is quite true that with such invalids a radical change of climate is not indispensable, and the principal advantage gained by a transition from a cold and damp region to a warm and dry one is attrib- 
utable to the fact that they are enabled to enjoy daily exercise in the open air without incurring the risk of taking colds; whereas, remaining at home, they would be deprived of proper exercise, confined to a large extent within doors, and exposed to manifold depressing conditions, such as tend to produce indigestion, fatty degeneration of the muscular tissue, and hypochondriasis.

Aiken is contra-indicated, according to Dr. Geddings, in laryngeal consumption ${ }^{1}$ and laryngitis on account of the dryness of the air, and for the same reason is inappropriate in bronchitis when attended with an irritable congh, with scanty, viscid expectoration. There are, moreover, certain diseases of the nervous system, characterized by excitability and irritability, not associated with much debility, where an atonic or sedative climate would undoubtedly prove more beneficial; and the same remark applies in that class of illnesses occurring more frequently to those in advanced years, where an enfeebled circulation fails to supply the requisite animal heat.

As a general rule, all visible indications of the damage inflicted upon any territory by warfare quickly disappear, but the greater part of South Carolina continues to this day to present a forcible picture of some of the results of our late civil strife, and the discreditable misgovernment with which it was supplemented. Deserted plantations, blackened ruins of farm-houses, dilapidated buildings, and prostrate fences all bear witness to the imporerishment of the people; and even in Charleston the same stagnant condition of affairs prevailed. In that city I observed that some of the oldest streets were quite destitute of pavement, and upon inquiry learned that the pavement formerly existing had been removed in the first year of the war, and employed in strengthening some of the defenses about the harbor; and the broad swath cut across the business portion of the city by the great fire of 1862 still retains its original outlines, almost no attempt having been made to restore the buildings then destroyed. Unlike the greater part of the State, however, Aiken presents an appearance of comparative thrift and prosperity. A unique feature of the town, and one which in the future must contribute to its sanitary advantages, is the magnificent scale upon which its streets are laid out, the width of the principal thoroughfares being one hundred and fifty feet, while the avenue upon which the principal hotel is situated has a uniform width of two hundred feet.

It is now generally conceded that in the treatment of certain diseases, notably in pulmonary complaints, asthma, whooping-cough, intermittent fever, and diseases characterized by dyspepsia, no more beneficial

1 In a critical notice of the work of Dr. Geddings, contained in a recent number of the Medical Record, the erroncous statement is made that the air of Aiken is inappropriate for all consumptives, as well as for all diseases of the nervous system. 
results can be obtained than those derived from a judicious change of climate; and yet the invalid should be made to understand that no climate either in the United States or Europe possesses all the physical qualities that could be desired. The winter and spring climate of Aiken, though greatly superior to that of our Northern cities, is by no means perfect, and the invalid, while seeking to avail himself of the health-giving influences afforded by the special advantages there offered, must at the same time be constantly on guard to eschew its disadvantages. Of the various sources of danger, the most prominent is that arising from exposure during one of the sudden transitions from heat to cold, which are not unfrequently encountered, It may not be superfluous, moreover, to warn the physician that diseases in all stages are not amenable to a change of climate. The serious error is too often made of sending away patients suffering from advanced organic disease attended, perhaps, with extreme physical weakness, and in no condition to sustain the fatigne inseparable from a long journey. In such cases an acute fever is produced by the inevitable exposure incident to traveling, and possibly some new inflammatory affection is developed, all of which more than neutralizes any benefit that could be derived from a residence in even the most appropriate climate.

Of Aiken it may be said, in conclusion, that its tonic, bracing climate differs in no essential particular from that of the health resorts of the Northern Mediterranean. The locality cannot fail in the future to enjoy a hygienic preëminence, for, while it indeed offers fewer sources of attraction than the foreign sanitaria, it is, on the other hand, much more accessible, and the comparatively low price at which a season can be spent there places its remedial advantages within the means of many whose moderate circumstances would preclude the idea of a foreign trip.

\section{A CASE OF HYDROPHOBIA.}

BX C. M. JONES, M. D.

Mrs. L. W. was a healthy woman of thirty-five. She had complained at times of palpitation, and had had occasional hysterical attacks, sometimes violent. On the 31 st of last July, a black and tan terrier belonging to her had been irritated by children until he finally bit one of them. She was whipping him for this offense, when he seized the second finger of the right hand so tightly that force was required to break his hold. He was turned into the street, and two other children were bitten before he was killed. He was not at any time supposed to be mad. Two of the four had their wounds cauterized immediately. Mrs. W. and the remaining one, who was bitten in the face, had nothing done. Subsequently she appeared cheerful, though her mother thinks 